\title{
Hotspots and Trends of Graduate Public Health Education Research in China
}

\author{
Sha Feng ${ }^{1}$, Jian Bai ${ }^{2}$, Jichun Zhang ${ }^{3} \&$ Song Lin $^{3}$ \\ ${ }^{1}$ Faculty of Medical Science, Jinan University, Guangzhou, China \\ ${ }^{2}$ School of Medicine, Jinan University, Guangzhou, China \\ ${ }^{3}$ Department of Physiology, School of Medicine, Jinan University, Guangzhou, China \\ All authors contributed equally to this work.
}

Correspondence: Song Lin \& Ji-chun Zhang, Department of Physiology, School of Medicine, Jinan University, Guangzhou 510632, China.

Funding: This work was supported by the 23th research projects of pedagogical reform at Jinan University (JG2021022).

Received: June 23, 2021

Accepted: October 13, 2021

Online Published: October 20, 2021

doi:10.5430/ijhe.v11n2p109

URL: https://doi.org/10.5430/ijhe.v11n2p109

\begin{abstract}
Academic research trends involving public health education may reflect a certain degree of talent construction status. This study systematically reviews the data for published literature on graduate public health education, aiming to provide evidence for the optimization of public health postgraduate training mechanisms in China. Keyword cooccurrence analysis was performed based on high-frequency keywords. From 1992 to 2008, the annual number of publications in this field was relatively low in China, averaging fewer than 5 articles. The number of publications showed a steep increase after 2009. The publications were mostly from single research institutions, including comprehensive universities and military medical universities, concentrated in Beijing and Shanghai. The high-frequency keywords were public health and preventive medicine, postgraduate training, professional degree, $\mathrm{MPH}$, curriculum, and teaching reform. Hotspots consisted of practical teaching research, training, educational reform and comparative education research. Research on public health postgraduate education has not reached scale and has insufficient support. Moreover, many problems in graduate public health education still cannot be solved by existing studies: authentic and practical learning, a unified approach to cultivate graduate students, organizational change of graduate public health education, and international cooperation and public health education.
\end{abstract}

Keywords: graduate education, public health, research hotspots, research trends, quantitative analysis

\section{Introduction}

According to the Chinese "Health and Family Planning Statistics Yearbook" (2018), over half (54\%) of China's public health professionals at the Centers for Disease Prevention and Control (CDCs) have graduated from a 3-year junior college, and approximately one-third of these professionals have earned a bachelor's degree. However, health professionals in China's CDCs who have received graduate education account for merely $10 \%$ (Zhan, 2020). In contrast, most professional training in public health worldwide has been at the graduate level. From a global viewpoint, graduate education is the core of public health professional development (White, 2013). In February 2020, the Ministry of Education and the National Development and Reform Commission proposed postgraduate student enrollment expansion, which focused on clinical medicine and public health high-level applied talent. There is an urgent need to explore the cultivation of public health talent to respond to societal needs.

Academic research trends involving public health education may reflect a certain degree of talent construction status. Research on public health talent training in China has been carried out by many scholars ( $\mathrm{Lu}, \mathrm{Li}, \&$ Fangmin, 2020; Tao, Jun, Canqing, \& Liming, 2020). Lu et al. (2020) suggested that cultivating public health talent is a rational way to implement the strategy of "Healthy China", but there are problems such as outdated training models, weak discipline construction levels, and insufficient theoretical research support. Tao et al. (2020) discussed the dilemmas and weaknesses that relate to the position of public health education in the higher education system, the public health education system, the curriculum system, teaching methods, practice-based teaching, training of highly qualified 
personnel in public health, public health teachers, remuneration and nonmonetary honorary rewards for the public health workforce. Several studies have documented hotspots, trends and the development of medical education in various fields (Yongsheng, Qichuan, \& Lingzhi, 2020; Chang et al., 2017). Yongsheng et al. (2020) conducted a literature review of medical education informatization research in the Chinese National Knowledge Infrastructure (CNKI) database as a sample, analyzing the research, status quo and development trends of medical education informatization in China, and found that research hotspots mainly focused on the three areas of teaching, medical education and information construction. Chang et al. (2017) retrieved literature published between 2012 and 2016 from PubMed using selected medical subject headings $(\mathrm{MeSH})$ terms and obtained 6 groups of high-frequency MeSH terms that reflected the domain hotspots. They concluded that all of these research topics could provide useful information for educators and researchers to conduct ongoing in-depth studies. However, the development process and research hotspots of graduate public health education have received little attention. This study systematically reviews the data for published literature on graduate public health education, aiming to provide evidence for the optimization of public health postgraduate training mechanisms in China.

\section{Methods}

\subsection{Data Source}

The authors retrieved published studies from the core collection of Web of Science, CNKI, Wanfang Data, and VIP online computer databases up to July 2020 using various search terms and their combinations, including public health, graduates, MPH, education, preventive medicine, and graduate education. Studies were additionally required to meet the following inclusion and exclusion criteria: English/Chinese language; inclusion of peer-reviewed articles consisting of case studies, editorials, literature review, and primary research studies; and exclusion of gray literature as these may not have gone through a peer review process. We considered all articles regardless of methodological approach, including both qualitative and quantitative methodologies.

\subsection{Study Selection}

The initial broad search criteria led to 781 articles. This number was then refined to 498, excluding conference proceedings, dissertations, newspaper articles, papers simultaneously published by different journals and translated foreign papers. Studies were limited to those focused on graduate public health education in China and excluded studies focused on education in other allied health fields (such as clinical medicine, basic medicine, oral medicine, pharmacy, traditional Chinese medicine, or nursing). In the process of literature selection, the title and abstract were read first, and the full text was then read to determine the final inclusion after excluding irrelevant publications. Eventually, a total of 249 articles were included in the final analysis. Figure 1 below shows the literature screening process.

\subsection{Data Analysis}

NoteExpress software was used for literature management and records searching. Keywords were extracted from the literature by using keyword cooccurrence analysis. After data collection, data were checked for completeness, entered into Excel for cleaning and transported to SPSS version 20 for analysis. A cluster analysis was conducted to reflect the relationship between keywords of high frequency.

\section{Results}

\subsection{Distribution of Total Annual Publications}

The annual numbers of published articles are shown in Figure 2, which, to a large extent, could outline the research trends and landscape of graduate public health education. Since the first publications documenting graduate public health education in 1992, the number of articles published has increased annually in China; the current decade has experienced explosive growth in relevant publications. A detailed description is as follows. (1) The bar chart revealed extraordinarily low reporting of graduate public health education in the English language literature. The overwhelming majority of the articles were published in Chinese with annual quantity changes. (2) The development of graduate public health education in 1992-2008 was relatively flat, and the annual numbers of publications were below 5 . Graduate public health education is an emerging topic that has received very little attention in this first stage. (3) After 2009, the amount of research literature showed a relatively more rapid increase. Interest in public health education has been growing over the past decades, with similar growth in the literature on graduate education in public health settings, which may correlate with practice-related policies at the national level.

\subsection{Distribution of Core Authors and Core Research Institutions}

The authors who had more than 5 articles in 1992-2020 are illustrated in Figure 3. (The authors mentioned below are 
all first authors.) Xiang He from the Training Department of the Second Military Medical University and Ling Wang from Fudan University Shanghai Medical College are the most productive authors in graduate public school education, with 9 articles each. Yonghua Hu, a professor of Peking University's School of Public Health, followed, with 8 articles. Dong Zhou and Fang Xu from the Training Department of the Second Military Medical University both published 7 articles. Luo, Li, Ge, Zhu and Wen each published 6 articles in graduate public school education, and others in this area have 5 articles. The core research institutions of graduate public school education research are concentrated in Beijing and Shanghai; they are mostly comprehensive universities and military medical universities. This indicates that all the above institutions have an influence in the field of graduate public school education.

\subsection{High-Frequency Keywords in Graduate Public Health Research}

Keywords, the series of concepts or phrases, play key roles in representing the central content of the academic literature (Yongsheng, Qichuan, \& Lingzhi, 2020). The research focus was accurately grasped by investigating the connection of keywords. The paper was classified by counting the frequency of their keywords, reading their full content, and refining their themes. As depicted in Table 1, we finally acquired 50 high-frequency keywords after eliminating the low-frequency keywords and incorporating synonymous keywords. Public health and preventive medicine, training mode, professional degree, master of public health (MPH), and curriculum setting are among the high-frequency keywords that are hot issues in graduate public health education in China.

\subsection{Keywords Cooccurrence Analysis}

By analyzing the connections between keywords of publications, the cooccurrence analysis identifies correlations and similarities that determine the contextual meaning of the keywords selected. As shown in Table 2, these network analyses are represented as a 50×50 cooccurrence matrix. The smaller the distance between two keywords, the larger the number of cooccurrences of the keywords. The numbers on the main diagonal indicate the frequency of corresponding keywords. For instance, a cluster of "Master of Public Health" included keywords with 57 occurrences, while "professional degree" appeared 28 times. The frequency with which these two keywords appear in the same paper is up to 14 repetitions, which illustrates the tight relationship between "Master of Public Health" and "professional degree".

Keyword clustering not only helps retrieve the required literature but also provides scholars with an in-depth understanding of the content of graduate public health education. Therefore, keyword clustering intuitively reflects the research hotspots and trends in China. The main research hotspots in the graduate public health education field are divided into four major groups based on cutting the dendrogram of the clustering (Figure 4). The research trend clusters are concentrated in the following areas. (1) Authentic and practical learning: Studies were conducted by analyzing students' satisfaction with practical teaching and the teaching practice of the course, e.g., health economics. (2) Talent cultivation: Existing papers evaluate multiple perspectives, such as training objectives, training quality, curriculum settings, and social practice, and discuss relevant influencing factors. (3) Educational reform: The scope covers the degree and school system, training mode, curriculum system construction, dissertation and innovation ability. (4) Comparative education research: Previous literature mainly compares professional education and enrollment models between Chinese and American medical schools.

\section{Discussion}

Given the lack of existing summaries, we aim to provide a metrological analysis of published approaches to the graduate public health education literature in China. The principal objective of this study is to provide insight into the current state of the literature on graduate public health education in China, synthesize current trends, and formulate recommendations on the future development of graduate public health education through an analysis of 237 published papers.

\subsection{Public Health Graduate Education Research in China Has Not Yet Reached Scale}

According to the growth rate of the annual number of documents, we divided the literature quantity levels into three stages. (1) The first stage is from 1992 to 2008, when the growth in the number of papers was relatively slow. At this stage, Chinese researchers gradually began to pay attention to the field of graduate public health education. (2) The second stage is from 2009 to 2014, when interest in graduate public health education steadily grew. The sizable increase in graduate public health education publications correlates with the pilot reform to MPH in China. In 2009, the Chinese government launched a comprehensive reform pilot work for professional degree education in the field of public health. The relevant policy proposed expanding the scale of training of high-level applied talent, especially full-time professional degree graduate education. The Ministry of Education initiated the MPH education reform in 2010. Peking University and Fudan University took the lead in enrolling full-time MPH students in China as the first 
pilot units. (3) The third stage is after 2015; there has been a dramatic increase in the number of graduate public health education studies over the last 5 years. Although the data for the first half of the year are counted in 2020, the number of published papers has also increased to 20. The key node event corresponding to this stage is the Outline of the "Healthy China 2030" Initiative issued by the Central Government of China in 2016. Public health graduate enrollment has included all part-time MPH enrollments and full-time MPH national enrollments since 2017. In 2017, the State Council called for a close correlation between the education of health professionals and the Chinese health system's demand for health professionals. This emphasizes a major aim of the education reform: to increase the supply of health professionals in high demand and improve the quality of training of those graduates (Hou et al., 2018). After the outbreak of the coronavirus disease 2019 (COVID-19) pandemic, China issued a number of national policies about educational reform, and various measurements have also been suggested since September 2020, such as "Guiding Opinions of the General Office of the State Council on Accelerating the Innovation and Development of Medical Education", "Opinions of the Ministry of Education and the National Development and Reform Commission of the Ministry of Finance on Accelerating the Reform and Development of Postgraduate Education in the New Era", and "General Office of the Ministry of Education and National Health Commission on the Implementation of High Notice on the Innovative Project of Training Hierarchical Applied Public Health Talents". At this stage, scholars' attention to public health graduate education and output results have increased significantly, providing theoretical support for and evidence of China's response to public health problems.

In general, the literature on graduate public health education in China is currently insufficient, especially research published in English. One possible reason for this is that the postgraduate education of public health in China did not begin until the late 1980s (Jun, Nan, Xi, \& Li-ming., 2010); another reason may be that the public health discipline was undervalued in long-term development. Moreover, neither had an international vision or international research teams been established; few English-language articles have been published on the topic of graduate public health education. Nevertheless, previous studies demonstrated that only $24(17.5 \%)$ of the 137 "double first-class" universities have schools of public health (Tao, Jun, Canqing, \& Liming, 2020). The outbreak and spread of COVID-19 have not only called people's attention to the importance of public health and infectious disease prevention but have also underscored the crucial role of the education and training of health professionals to tackle public health emergencies.

Through the analysis of core authors and research institutions, it was found that there are few prolific authors and that the research forces are scattered. Research institutions are mostly medical schools in Beijing and Shanghai, indicating that the development of graduate public health education is markedly uneven between areas. This low proportion of interinstitutional collaboration may suggest the lack of cooperation between regional scientific communities. It is therefore critical to promote institutional cooperation among different research institutions so that scholars in the graduate public health education field can create more cross-institutional and cross-disciplinary collaborative teams.

\subsection{Public Health Graduate Education Research in China Has Limited Guidance}

In the clustering, the high-frequency keywords are initially divided into four major research hotspots, all of which overlap, which indirectly reflects the fact that the research content of public health graduate education in China is relatively one-dimensional. Most of the existing literature consists of subjective comments in the form of reviews, with few theoretical studies and few high-quality quantitative studies supported by data. In the future development of public health postgraduate education in China, more attention should be paid to the diversification of research methods and topics based on current circumstances and policy orientation. Research methods should be reasonably selected according to the research purpose, and the inference of causation among the variables, thus, should be explained with caution. In the following, we will further discuss the four hotspots detected by the literature in the field of graduate public health education in more detail.

\subsubsection{Authentic and Practical Learning}

Practical teaching research includes teaching reform and practice of courses such as "Health Economics" and "Introduction to Environmental Medicine", as well as the exploration and practice of training models, degree program evaluation, empirical analysis of student satisfaction, and the base of social practice. Public health is a professional, intellectual and applied specialization, oriented to promote practical applications, which can be clearly differentiated from basic disciplines. The unprecedented interruption of practical education due to COVID-19 has accelerated innovation and exacerbated challenges. Much attention has been given to authentic and practical learning in the post-COVID-19 era. The course requirements, specialization options, and practical training components are all based on the demand for practical skills. Future efforts to actively expand public health practical teaching bases are 
encouraged to improve students' public health emergency-response ability, occupational attainment and professional quality by strengthening cooperation with the government, CDCs, health supervision agencies, hospitals, community health service centers and other units. The importance of interprofessional health education (IPE), especially as public health education expands in China, should be given much attention. Practicum experience aligns well with competency-based public health education, which stresses the importance of continuous improvement. Further exploration is needed to connect MPH education and standardized training of public health physicians, develop innovative training models for public health practitioners' competency, increase public health knowledge of hospital managers, and cultivate public health talent urgently needed and highly recognized by society.

\subsubsection{Talent Cultivation}

The high-frequency keywords in the field of graduate public health education are always found to rank first in terms of training mode and postgraduate education. High-level applied public health talent cultivation was reported earlier in 1992 (Luo, 1992), partly owing to the principle of "prevention first" in China and the context of rapid changes in health policy. Since the late 1980s, departments of preventative medicine began establishing schools of public health. The development of the health system has always been considered a priority in China's development agenda. The exploration and thinking on the cultivation of different degree types of postgraduates, as well as the analysis of influencing factors such as student performance and scientific research ability in past literature, have been described. The Commission on the Education for Health Professionals for the 21st Century reported that although $73 \%$ of the articles on health professional education address medical education and $25 \%$ nursing education, only $2 \%$ address public health education (Frenk et al., 2010). There have been few efforts to offer a unifying approach to the concepts that may underlie graduate public health education (Sullivan \& Galea, 2017). Currently, Chinese society needs high-quality talent oriented toward on-the-ground jobs in a variety of public health settings. The primary objective was to identify national health priorities for research, development and innovation for a high-level public health personnel training system that would be a direction for future study at the national level. This point will be continually studied in the future, including optimizing training programs, improving training quality, expanding training scales, and exploring ways to integrate top application-oriented talent. With the growing trend of variation in learning and diverse formats for academic programs, we should innovate professional programs, such as improving the talent training system for the Master of Public Health (MPH) programs and creating training programs for the Doctor of Public Health (DrPH). Public health has a critical role to play in furthering IPE, while IPE-related activities have initiated, for instance, an IPE pilot program for MPH students.

\subsubsection{Educational Reform}

Educational reform, occupying distinguished branches of clustering analysis, has been the focus of much research. As early as 1988, scholars conducted research on the reform of public health graduate education and published the research results in 1992 (Qin \& Hu, 1992); the paper explored the public health graduate education model with Chinese characteristics and discussed the necessity of reform and reform attempts. Teaching reform is an important component of postgraduate education in public health. Relevant research is often linked with research on degrees and educational systems, training models, curriculum system construction, dissertations, and innovation capabilities. To meet these challenges in the post-COVID-19 era, competent public health professionals are urgently needed by Chinese society. However, there is still a shortage of public health professionals in China. Epidemiology, statistics, laboratory testing and other disciplines of public health provide scientific evidence for disease prevention and control. At present, the scale of epidemiological investigators and laboratory testers in China is insufficient. Under these circumstances, it is essential to equip future physicians with knowledge of disease prevention and support their ability to deal with public health emergencies, which will be crucial to promote the medical/education/health collaborative education mechanism. Moreover, the COVID-19 pandemic has forced a shift from teaching and learning, as new technologies support flexibility with remote and online teaching and learning (Sullivan, Velez, \& Galea, 2020). Instructors and health professionals are exploring innovative methods to deliver IPE programs in online education, and related literature has demonstrated that IPE increases awareness of team members' roles and enhances communication and collaboration (Singh J\& Matthees B, 2021). There are several directions that can be explored in future work, such as redesigning core curricula to include several integrated core courses, creating interdisciplinary specialization options, exploring " $\mathrm{MPH}+\mathrm{X}$ " dual degree programs, and taking advantage of emerging technologies to promote active learning (Hunter, Lapp, \& Frenk, 2014;Ngoc, Hoang, \& Hung, 2020).

\subsubsection{Comparative Education Research}

This kind of research began to take place in the early 21 st century. Descriptions of the public health graduate education system and practice in the United States and other countries provide a beneficial reference for public 
health graduate education in China. Without a doubt, comparative education research is conducive to providing information for domestic education professionals, broadening their horizons, inspiring thinking, and further improving the level of public health education in China. While there is mounting agreement about the merits of international experience, there is little consensus about how to educate graduate students with Chinese characteristics. Considering the magnitude of China's experiences in response to COVID-19, the country has great potential to serve as a role model for other countries in public health education, guided by "a global community of health for all" based on China's practice. It is suggested that future studies focus on Chinese characteristics, in line with international standards, to investigate a multidimensional high-level applied public health personnel training model.

\subsection{Research on Humanistic Education for Graduate Students Is Relatively Lacking}

Although humanism in medical students has received greater attention in recent years, its educational functions have not been broadly studied. There are few previously published reviews synthesizing the literature on the core humanistic competencies for developing humanistic education for graduate students in public health (Ke, Zirui, \& Yijie, 2020). Public health education practitioners need to incorporate the work of researchers in philosophy, history and literature into the teaching process; moreover, additional studies with overarching themes from critiques, fieldwork, oral histories and much more comprehensive literature reviews are warranted (Buchanan, 1998).

\section{Conclusion}

Compared with many earlier studies, this study employed quantitative analysis using precise algorithms to calculate hotspots and trends. This study can provide insight into the current state of the literature on graduate public health education in China, synthesize current trends, and formulate recommendations on the future development of graduate public health education. According to the above analysis, many problems in graduate public health education still cannot be solved by existing studies: authentic and practical learning, a unifying approach to cultivate graduate students, organizational change of graduate public health education, and international cooperation of public health education. With regard to the research methods, this study was limited in several ways. This study excluded conference proceedings and dissertations, which might pose a potential risk of publication bias. In addition, some synonymous keywords were merged based on the authors' understandings, and some may have been incorrectly done, leading to misclassification. If we want to understand the theory and process of graduate public health education in an objective and comprehensive way, the empirical investigation can be done by means other than document studies, such as using focus group discussions, key informant interviews, and questionnaire surveys.

\section{References}

Buchanan, D. (1998). Beyond positivism: Humanistic perspectives on theory and research in health education. Health Education Research - HEALTH EDUC RES, 13, 439-450. https://doi.org/10.1093/her/13.3.439

Chang et al. (2017). Hotspots in research on the measurement of medical students' clinical competence from 2012-2016 based on co-word analysis. BMC Medical Education, 17(1), 162. https://doi.org/10.1186/s12909-017-0999-8

Frenk et al. (2010). Health professionals for a new century: transforming education to strengthen health systems in an interdependent world. [Consensus Development Conference; Journal Article; Research Support, Non-U.S. Gov't]. Lancet, 376(9756), 1923-1958. https://doi.org/10.1016/S0140-6736(10)61854-5

Hou et al. (2018). Public health education at China's higher education institutions: a time-series analysis from 1998 to 2012. BMC Public Health, 18(1), 679. https://doi.org/10.1186/s12889-018-5605-4

Hunter, D. J., Lapp, I., \& Frenk, J. (2014). Education in public health: expanding the frontiers. [Editorial; Research $\begin{array}{lllllllll}\text { Support, U.S. Gov't, } & \text { P.H.S.]. Am } J \text { Prev } & \text { Med, } 47(5 & \text { Suppl 3), } & \text { S286-S287. }\end{array}$ https://doi.org/10.1016/j.amepre.2014.07.047

Jun, L., Nan, C., Xi, L., \& Li-ming, L. (2010). A survey of the master of public health （MPH） program in China. Chinese Journal of Medical Education, 05, 771-774

Ke, H., Zirui, D., \& Yijie, L. (2020). A Study on the Innovation of Ideological and Political Work of Medical Graduate Students. HEALTH VOCATIONAL EDUCATION, 38(08), 38-41

Lu, S., Li, L., \& Fangmin, X. (2020). Problems and Countermeasures of Public Health Talent Cultivation: Thinking Based on the COVID-19 Epidemic. China Higher Education Research, 05, 48-51

Luo, J. (1992). Reforming Public Health Education, Cultivating Senior Applied Public Health Talent. Medical Education(China), 11, 5-8. 
Ngoc, H., Hoang, L., \& Hung, V. (2020). Transforming Education with Emerging Technologies in Higher Education: A Systematic Literature Review. International Journal of Higher Education, 9, 252. https://doi.org/10.5430/ijhe.v9n5p252

Qin, H., \& Hu, Z. (1992). On the Reform of Postgraduate Education of Public Health. Journal of Shandong Medical University (Social Science Edition), 02, 12-14.

Singh, J., \& Matthees, B. (2021). Facilitating Interprofessional Education in an Online Environment during the COVID-19 Pandemic: A Mixed Method Study. Healthcare, 9(5), 567. https://doi.org/10.3390/healthcare9050567

Sullivan, L. M., Velez, A. A., \& Galea, S. (2020). Graduate public health education in the post-COVID-19 era. [Letter; Comment]. Lancet Public Health, 5(9), e473. https://doi.org/10.1016/S2468-2667(20)30181-X

Sullivan, L., \& Galea, S. (2017). A Vision for Graduate Public Health Education. Public Health Manag Pract, 23(6), 553-555. https://doi.org/10.1097/PHH.0000000000000664

Tao, R., Jun, L., Canqing, Y., \& Liming, L. (2020). Rethinking public health education and public health workforce development in China. Chinese Journal of Preventive Medicine, 05, 457-458.

White, F. (2013). The Imperative of Public Health Education: A Global Perspective. Research Support, Non-U.S. Gov't; Review]. Med Princ Pract, 22(6), 515-529. https://doi.org/10.1159/000354198

Yongsheng, W., Qichuan, H., \& Lingzhi, S. (2020). Status quo and development trend of domestic medical education informatization research:A visual analysis based on CiteSpace. China Medical Education Technology, 34(01), 24-28.

Zhan Qimin. (2020). Executive Vice President Of Peking University Director Of The Medical Department, A. O. T. C. (2020). Thoughts on training public health talents in the post-epidemic era, China Youth Daily, p. 4. Retrieved from http://kns.cnki.net/KCMS/detail/detail.aspx?FileName=ZGQN202004270060\&DbName=CCND2020 


\section{Appendix}

Table 1. High-frequency keywords in graduate public health research.

\begin{tabular}{|c|c|c|c|c|c|c|c|c|}
\hline No. & Keywords & Frequency & No. & Keywords & Frequency & No. & Keywords & Frequency \\
\hline 1 & $\begin{array}{l}\text { public health and } \\
\text { preventive } \\
\text { medicine }\end{array}$ & 94 & 18 & comparison & 5 & 35 & medical school & 3 \\
\hline 2 & $\begin{array}{c}\text { Master of } \\
\text { Public } \\
\text { Health }\end{array}$ & 57 & 19 & $\begin{array}{l}\text { public health } \\
\text { emergency }\end{array}$ & 5 & 36 & satisfactions & 3 \\
\hline 3 & postgraduate & 45 & 20 & $\begin{array}{l}\text { training } \\
\text { quality }\end{array}$ & 5 & 37 & $\begin{array}{c}\text { health } \\
\text { management }\end{array}$ & 3 \\
\hline 4 & training mode & 36 & 21 & $\begin{array}{l}\text { influencing } \\
\text { factor }\end{array}$ & 5 & 38 & $\begin{array}{c}\text { innovation } \\
\text { ability }\end{array}$ & 3 \\
\hline 5 & $\begin{array}{l}\text { graduate } \\
\text { education }\end{array}$ & 34 & 22 & $\begin{array}{l}\text { doctoral } \\
\text { students }\end{array}$ & 4 & 39 & academic leader & 3 \\
\hline 6 & $\begin{array}{c}\text { professional } \\
\text { degree }\end{array}$ & 28 & 23 & $\begin{array}{l}\text { public health } \\
\text { education }\end{array}$ & 4 & 40 & education & 3 \\
\hline 7 & MPH & 14 & 24 & $\begin{array}{l}\text { academic } \\
\text { dissertation }\end{array}$ & 4 & 41 & $\begin{array}{l}\text { Health } \\
\text { economics }\end{array}$ & 2 \\
\hline 8 & United States & 12 & 25 & enrollment & 4 & 42 & $\begin{array}{c}\text { Military } \\
\text { medical college }\end{array}$ & 2 \\
\hline 9 & $\begin{array}{l}\text { graduate } \\
\text { culturing }\end{array}$ & 10 & 26 & course system & 4 & 43 & $\begin{array}{c}\text { health } \\
\text { supervisor }\end{array}$ & 2 \\
\hline 10 & medical statistics & 7 & 27 & $\begin{array}{l}\text { educational } \\
\text { model }\end{array}$ & 4 & 44 & mode & 2 \\
\hline 11 & $\begin{array}{l}\text { school of public } \\
\text { health }\end{array}$ & 7 & 28 & curriculum & 4 & 45 & $\begin{array}{l}\text { Degree } \\
\text { program }\end{array}$ & 2 \\
\hline 12 & China & 7 & 29 & $\begin{array}{c}\text { training } \\
\text { objective }\end{array}$ & 4 & 46 & assessment & 2 \\
\hline 13 & $\begin{array}{l}\text { curriculum } \\
\text { setting }\end{array}$ & 7 & 30 & innovation & 3 & 47 & mental health & 2 \\
\hline 14 & epidemiology & 7 & 31 & $\begin{array}{c}\text { social } \\
\text { practice }\end{array}$ & 3 & 48 & practice & 2 \\
\hline 15 & full-time & 7 & 32 & $\begin{array}{c}\text { John Hopkins } \\
\text { University }\end{array}$ & 3 & 49 & $\begin{array}{l}\text { enrollment } \\
\text { mode }\end{array}$ & 2 \\
\hline 16 & reform & 6 & 33 & $\begin{array}{l}\text { hygiene } \\
\text { toxicology }\end{array}$ & 3 & 50 & medical school & 2 \\
\hline 17 & $\begin{array}{l}\text { Medical } \\
\text { education }\end{array}$ & 6 & 34 & research & 3 & & & \\
\hline
\end{tabular}


Table 2. A partial matrix plot for co-occurrence analysis of high-frequency keywords.

\begin{tabular}{|c|c|c|c|c|c|c|c|c|c|c|}
\hline & $\begin{array}{l}\text { public health and } \\
\text { preventive medicine }\end{array}$ & $\begin{array}{l}\text { Master of } \\
\text { Public Health }\end{array}$ & postgraduate & $\begin{array}{l}\text { training } \\
\text { mode }\end{array}$ & $\begin{array}{l}\text { graduate } \\
\text { education }\end{array}$ & $\begin{array}{c}\text { professional } \\
\text { degree }\end{array}$ & $\mathrm{MPH}$ & $\begin{array}{l}\text { United } \\
\text { States }\end{array}$ & $\begin{array}{l}\text { graduate } \\
\text { culturing }\end{array}$ & $\begin{array}{l}\text { medical } \\
\text { statistics }\end{array}$ \\
\hline $\begin{array}{l}\text { public health and } \\
\text { preventive } \\
\text { medicine }\end{array}$ & 94 & 9 & 20 & 9 & 14 & 8 & 3 & 4 & 4 & 2 \\
\hline $\begin{array}{l}\text { Master of Public } \\
\text { Health }\end{array}$ & 9 & 57 & 4 & 13 & 6 & 14 & 2 & 4 & 2 & 1 \\
\hline postgraduate & 20 & 4 & 45 & 4 & 8 & 4 & 0 & 1 & 0 & 4 \\
\hline training mode & 9 & 13 & 4 & 36 & 7 & 4 & 3 & 2 & 0 & 0 \\
\hline $\begin{array}{l}\text { graduate } \\
\text { education }\end{array}$ & 14 & 6 & 8 & 7 & 34 & 4 & 3 & 0 & 0 & 0 \\
\hline $\begin{array}{l}\text { professional } \\
\text { degree }\end{array}$ & 8 & 14 & 4 & 4 & 4 & 28 & 2 & 1 & 1 & 0 \\
\hline MPH & 3 & 2 & 0 & 3 & 3 & 2 & 14 & 0 & 0 & 0 \\
\hline United States & 4 & 4 & 1 & 2 & 0 & 1 & 0 & 12 & 2 & 0 \\
\hline $\begin{array}{l}\text { graduate } \\
\text { culturing }\end{array}$ & 4 & 2 & 0 & 0 & 0 & 1 & 0 & 2 & 10 & 0 \\
\hline medical statistics & 2 & 1 & 4 & 0 & 0 & 0 & 0 & 0 & 0 & 7 \\
\hline $\begin{array}{l}\text { school of public } \\
\text { health }\end{array}$ & 2 & 2 & 2 & 1 & 1 & 0 & 0 & 0 & 1 & 0 \\
\hline China & 3 & 3 & 2 & 2 & 0 & 0 & 0 & 5 & 0 & 0 \\
\hline $\begin{array}{l}\text { curriculum } \\
\text { setting }\end{array}$ & 2 & 4 & 2 & 2 & 0 & 1 & 0 & 0 & 0 & 1 \\
\hline epidemiology & 1 & 0 & 1 & 0 & 2 & 0 & 0 & 2 & 1 & 0 \\
\hline
\end{tabular}

Figure 1. Diagram of the study selection process.

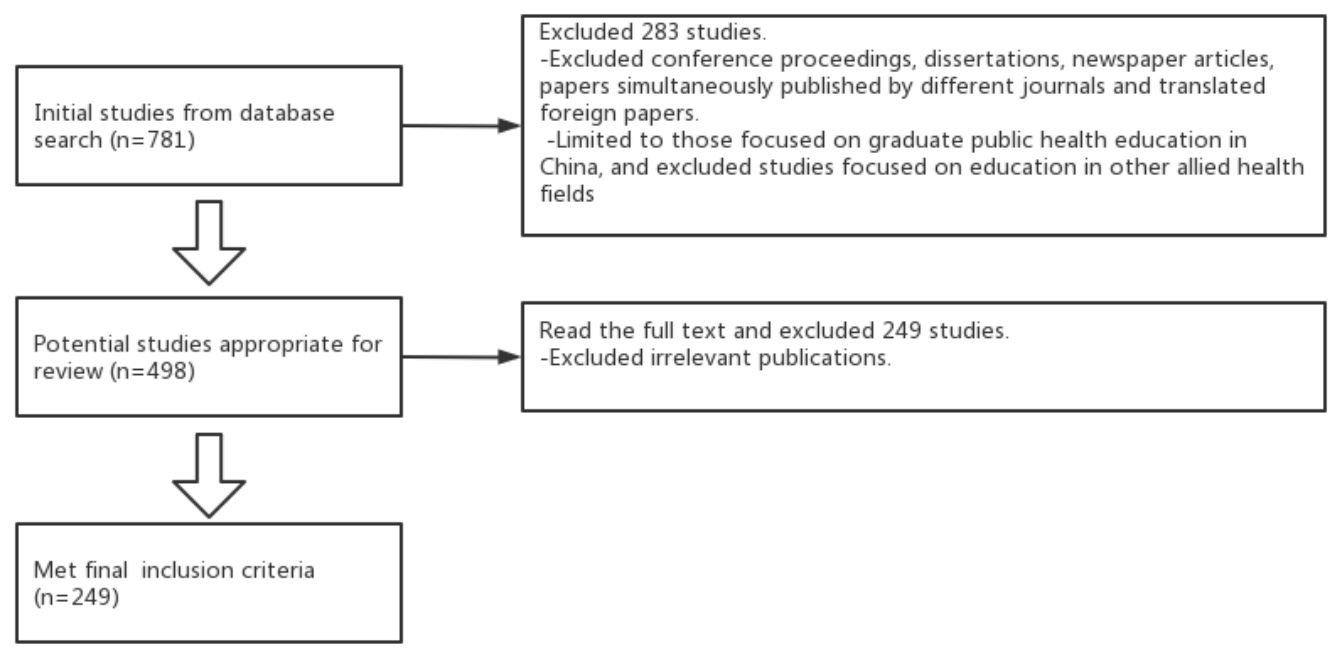


Figre 2. The annual numbers of Chinese articles in graduate public health education.

The bar chart shows the number and trend of graduate public health education research in China (1992-Mid 2020), in which English/Chinese language was marked.

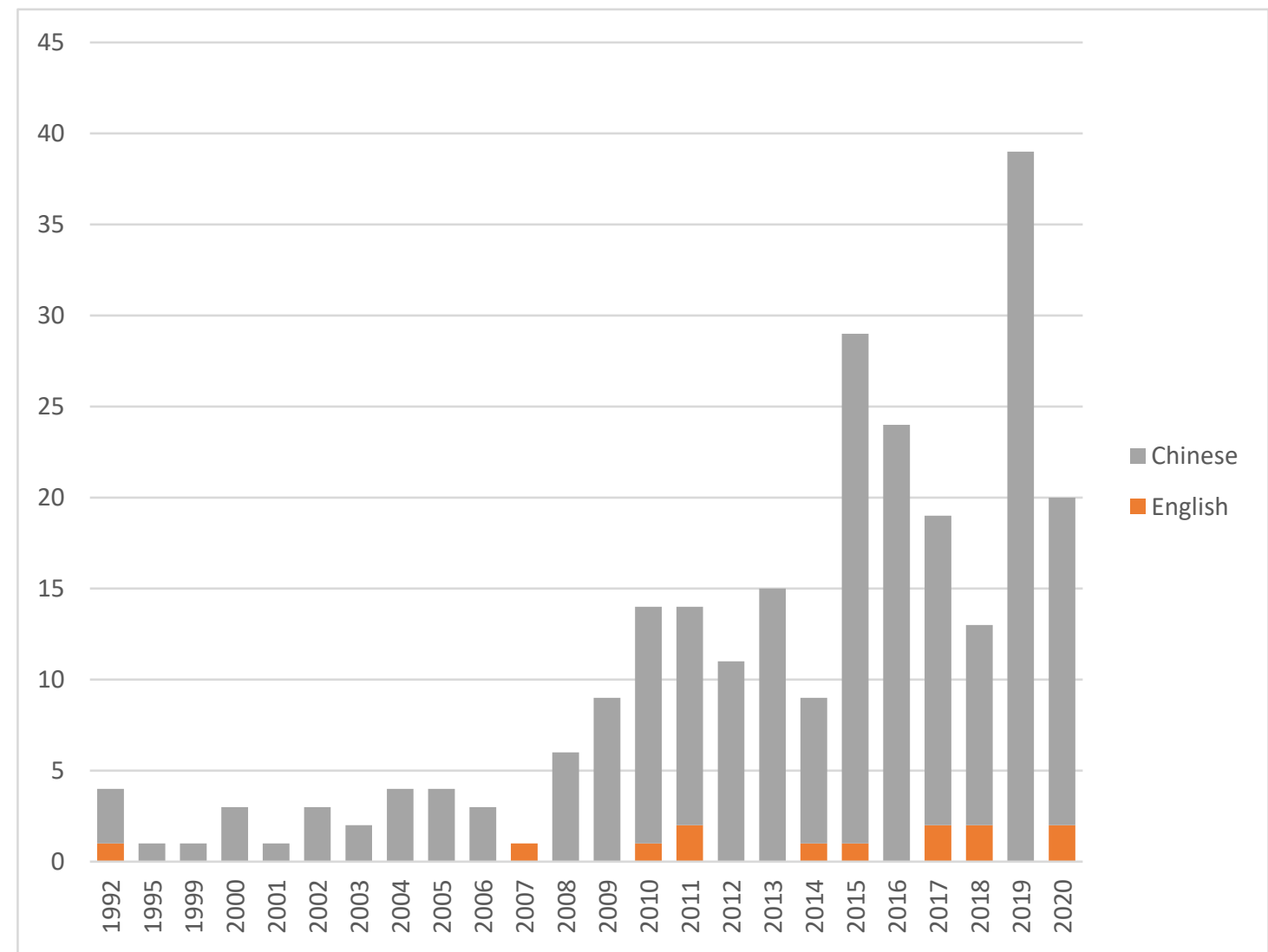

Figure 3. Radar chart of distribution of representative researchers and institutions.

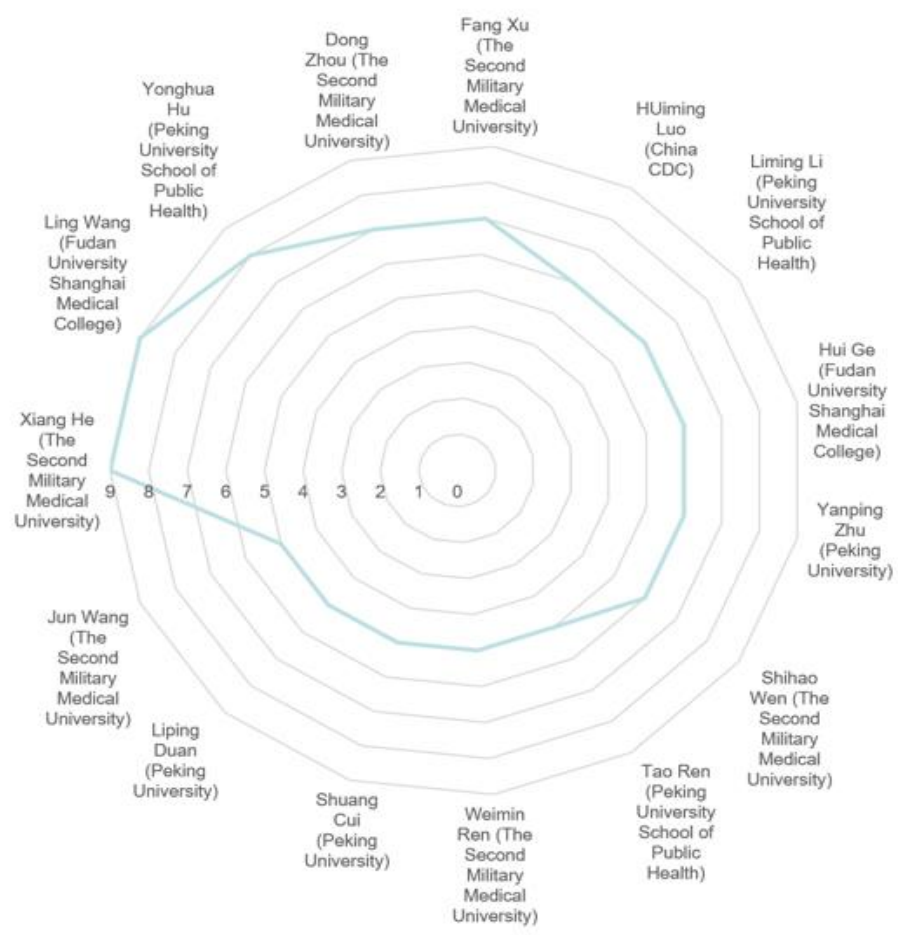


Figure 4. A dendrogram of the keyword clustering.

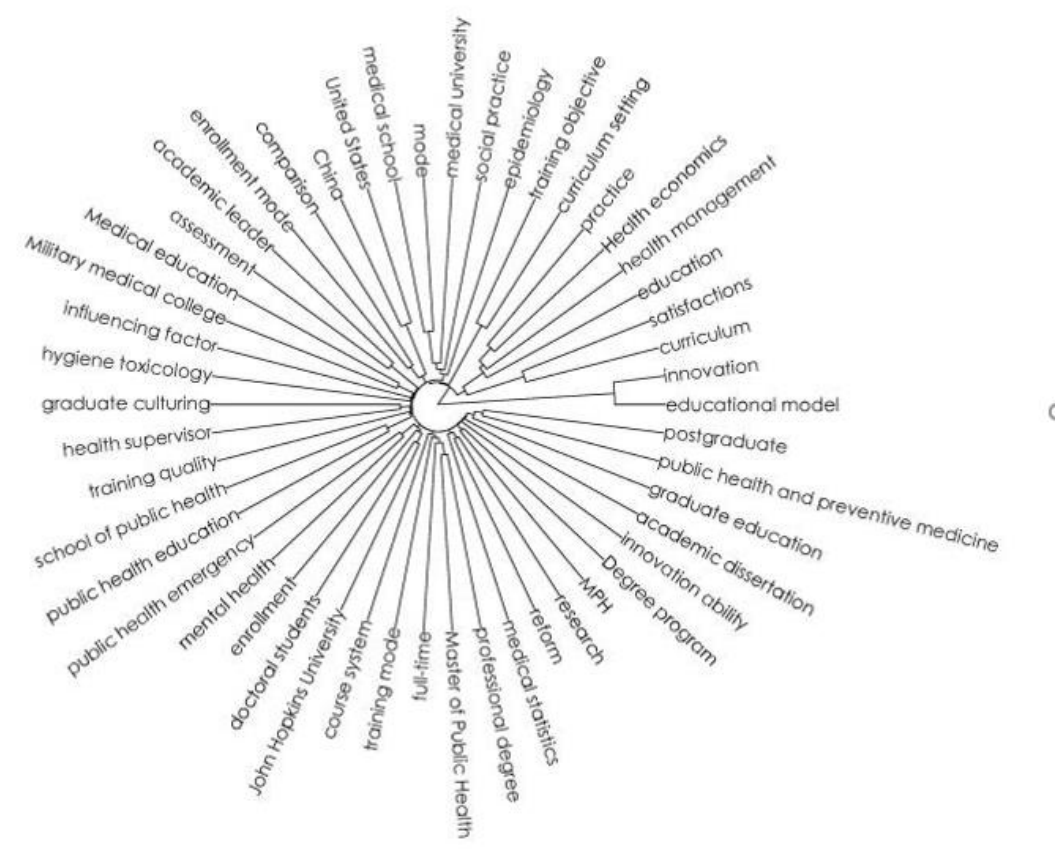

\section{Copyrights}

Copyright for this article is retained by the author(s), with first publication rights granted to the journal.

This is an open-access article distributed under the terms and conditions of the Creative Commons Attribution license (http://creativecommons.org/licenses/by/4.0/). 